\title{
Prevalence of asthma symptoms, diagnosis, and treatment in 12-14 year old children across Great Britain (international study of asthma and allergies in childhood, ISAAC UK)
}

Balvinder Kaur, H Ross Anderson, Jane Austin, Michael Burr, Leigh S Harkins, David P Strachan, John O Warner

Department of

Public Health

Sciences, St

George's Hospital

Medical School,

London SW17 0RE

Balvinder Kaur,

clinical lecturer in

public health medicine

H Ross Anderson,

professor of

epidemiology and

public health

Leigh S Harkins,

statistician

David P Strachan,

reader in

epidemiology

Highland

Communities NHS

Trust, Child Health

Department, Royal

Northern Infirmary,

Inverness IV3 5SF

Jane Austin,

community

paediatrician

associate specialist

Centre for Applied Public Health

Medicine, Temple of

Peace and Health,

Cathays Park,

Cardiff CF1 3NW

Michael Burr,

senior lecturer in

public health medicine

Southampton

General Hospital,

Southampton

S016 6YD

John O Warner,

professor of child

health

Correspondence to: Dr Kaur

BMJ 1998;316:118-24

\begin{abstract}
Objective: To investigate variations in the prevalence of self reported symptoms, diagnosis, and treatment of asthma in 12-14 year old children.

Design: Self completion questionnaire.

Setting: Great Britain.

Subjects: All pupils aged 12-14 years in a stratified cluster sample of 93 large mixed secondary schools in 1995.
\end{abstract}

Main outcome measures: Self reported prevalence of symptoms, diagnosis, and treatment of asthma at four geographical levels.

Results: 27507 questionnaires were completed (85.9\% response rate). The national 12 month prevalence of any wheezing, speech limiting wheeze, four or more attacks of wheeze, and frequent night waking with wheeze was $33.3 \%(\mathrm{n}=9155), 8.8 \%$ (2427), 9.6\% (2634), and 3.7\% (1023) respectively. The prevalence of ever having had a diagnosis of asthma was $20.9 \%$ (5736). In total, $19.8 \%$

(5438/27 507) of pupils reported treatment with anti-asthma drugs in the past year, but, of pupils reporting frequent nocturnal wheeze in the past year, $33.8 \%(342 / 1012)$ had no diagnosis of asthma and $38.6 \%$ (395/1023) denied receiving inhaler therapy. The 12 month prevalence of wheeze was highest in Scotland (36.7\%, 1633/4444), but in England and Wales there was no discernible north-south or east-west gradient. Wheeze prevalence was slightly higher in non-metropolitan areas $(35.0 \%$, $6155 / 17605)$ than in metropolitan areas $(30.3 \%$, 3000/9902). The prevalence of self reported asthma diagnosis and inhaler use showed no discernible national, regional, north-south, or east-west geographical pattern but was higher in non-metropolitan areas.

Conclusion: Prevalence of self reported symptoms, diagnosis, and treatment of asthma was high among 12-14 year olds throughout Great Britain with little geographical or urban-rural variation. Underdiagnosis and undertreatment were substantial.

\section{Introduction}

In Britain asthma is the commonest chronic childhood disease. ${ }^{1}$ Time trends show that the prevalence of childhood asthma and wheeze, however defined, has risen over the past few decades. ${ }^{2-5}$ The size of the increase varies, but cohort studies indicate a rise of $70 \%$ in the prevalence of wheezing illness at age 16 between 1974 and $1986 .{ }^{5}$ Despite speculation about which environmental and medical factors may account for this trend, the aetiology of asthma and wheeze remains unknown. ${ }^{6}$

The international study of asthma and allergies in childhood (ISAAC) has established a standardised methodology to compare the prevalence and severity of asthma and atopic diseases in children, both within and between countries. ${ }^{8}$ The study aims to describe the prevalence of these diseases and their symptoms, to provide a baseline for assessing future trends, and to identify whether there is sufficient variation in prevalence of symptoms to allow efficient testing of aetiological hypotheses either within or between countries. As part of this worldwide collaboration, we investigated geographical variations in the current prevalence and severity of asthma symptoms, diagnosis, and treatment across Great Britain.

\section{Methods}

In accordance with the ISAAC protocol, ${ }^{8}$ we obtained secondary school lists from departments of education in England, Wales, and Scotland. School years 8-9 in England and Wales and S2-S3 in Scotland contained most 13-14 year old pupils. We prepared sampling frames of mixed sex, state schools with over 100 pupils in each school year for every county (region in Scotland) and for four randomly sampled districts from the six metropolitan counties-West Midlands, Merseyside, Greater Manchester, South Yorkshire, West Yorkshire, and Tyne and Wear. We also prepared separate sampling frames for Glasgow, Edinburgh, and eight randomly sampled inner and outer London boroughs.

We randomly selected one school from each sampling frame and repeated this process until a 


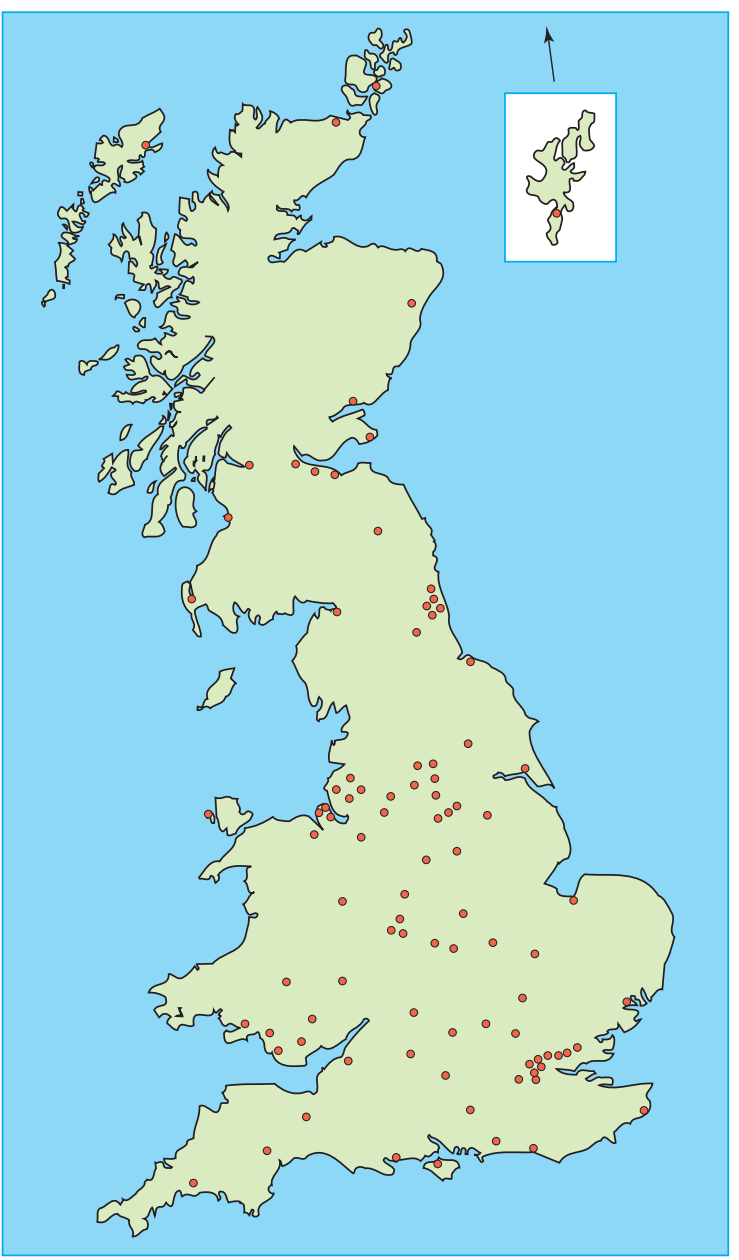

Location of the 93 schools that took part in study

school from each area agreed to participate (93 schools). We obtained approval for the study from each relevant local research ethics committee. In the selected schools all pupils in school years 8-9 or S2-S3 were eligible, including those aged 12 . We sent an explanatory letter to the children's parents, with a reply slip to return if they did not wish their child to participate. Pupils completed their confidential, anonymous questionnaire, supervised by a researcher or teacher with scripted instructions and answers, and then sealed it in an envelope for collection. The questionnaire contained standard ISAAC questions for self completion about symptoms of wheeze and asthma, ${ }^{89}$ and these were supplemented by questions on coughs, colds, indoor environment, smoking, demography, and birthplace (see appendix. for respiratory questions).

We explored the geographical patterns of prevalence at four levels - national, metropolitan versus nonmetropolitan areas, quadrants of England and Wales, and NHS regions of England (as identified in 1993). Metropolitan areas consisted of London, Glasgow, Edinburgh, and the six English metropolitan counties. Quadrants of England and Wales were identified by marking an east-west line at the latitude of the Wash and a north-south line extending from the Pennines southwards.

\section{Statistical analysis}

We analysed the data using $\mathrm{SAS},{ }^{10}$ Clinstat, ${ }^{11}$ and StatXact ${ }^{12}$ statistics packages. In accordance with ISAAC policy, we included "missing" or inapplicable responses in denominators for univariate analyses but excluded them from subsequent bivariate analyses. We calculated prevalence figures and differences in prevalence using data at both individual level ( $\chi^{2}$ test) and school level (Student's $t$ tests) to assess the effect of cluster sampling. The prevalence results and differences by age, sex, and birth abroad are based on individual level analyses, as cluster sampling had little effect. Cluster sampling had a greater impact on differences in prevalence between areas, however, which we therefore assessed by more conservative two sample $t$ tests on school level prevalences, unadjusted for school size.

\section{Results}

The figure shows the distribution of the schools across Great Britain. The response rate from schools (78.2\%) and pupils (85.9\%) did not differ significantly between areas (table 1). The ratio of girls to boys was similar across areas, but respondents in Scotland were older than those in England and Wales, and in Scotland and non-metropolitan areas fewer children were born overseas.

\section{Prevalence of symptoms}

There were few missing answers (table 2), but there were some inconsistent ones. For example, 4\% (1091/ 27507 ) reported that they had experienced wheeze with or without colds in the past 12 months (responded yes to questions 9 or 10), but they had previously answered no to question 2 , stating that they had not had any wheeze in the past 12 months. Much fewer showed inconsistency in their answers to questions 3-5

Table 1 Response and characteristics of participants (values are numbers (percentages) unless stated otherwise

\begin{tabular}{|c|c|c|c|c|c|c|c|}
\hline \multirow[b]{2}{*}{ Geographical area } & \multicolumn{2}{|c|}{ Response } & \multicolumn{3}{|c|}{ Age (years) } & \multirow[b]{2}{*}{ Male } & \multirow[b]{2}{*}{$\begin{array}{l}\text { Born outside } \\
\text { Great Britain }\end{array}$} \\
\hline & Schools & $\begin{array}{l}\text { Pupils in participating } \\
\text { schools }\end{array}$ & $<13$ & 13 & $>13$ & & \\
\hline Great Britain & $93 / 119$ (78.2) & $27507 / 32033$ (85.9) & $5804(21.1)$ & $13891(50.5)$ & $7812(28.4)$ & $13533(49.2)$ & $1045(3.8)$ \\
\hline Wales & $8 / 8(100)$ & $2351 / 2729$ (86.1) & $567(24.1)$ & $1227(52.2)$ & $557(23.7)$ & $1138(48.4)$ & $113(4.8) \dagger$ \\
\hline Scotland & $14 / 20(70.0)$ & 4 444/5 252 (84.6) & $89(2.0)$ & $2111(47.5)$ & $2244(50.5)$ & $2266(51.0)$ & $80(1.8) \dagger$ \\
\hline
\end{tabular}

${ }^{*}$ Number of schools or pupils participating divided by number that were approached.

$t \chi^{2}$ test $=60.1, P<0.0001$ comparing pupils between countries.

$\ddagger$ Yates' corrected $\chi^{2}$ test $=144, P<0.0001$ comparing pupils between metropolitan and non-metropolitan areas. 
Table 2 Geographical distribution of self reported wheeze and asthma in schoolchildren aged 12-14 years in Great Britain

Wheeze in past 12 months

In absence of a cold

\begin{tabular}{|c|c|c|c|c|c|c|c|c|c|c|c|}
\hline \multirow[b]{2}{*}{ Geographical area } & \multirow[b]{2}{*}{$\begin{array}{c}\text { Ever } \\
\text { experienced } \\
\text { wheeze }\end{array}$} & \multicolumn{7}{|c|}{ Wheeze in past 12 months } & \multirow[b]{2}{*}{$\begin{array}{l}\text { Ever had } \\
\text { asthma }\end{array}$} & \multicolumn{2}{|c|}{ In absence of a cold } \\
\hline & & Any & $\geqslant 4$ attacks & $\begin{array}{c}>1 \text { night per } \\
\text { week } \\
\text { disturbed }\end{array}$ & $\begin{array}{l}\text { Speech } \\
\text { limiting }\end{array}$ & $\begin{array}{l}\text { Moderate or } \\
\text { greater } \\
\text { disruption } \\
\text { of daily } \\
\text { activities }\end{array}$ & $\begin{array}{l}\text { Exercise } \\
\text { induced }\end{array}$ & $\begin{array}{l}\text { In absence } \\
\text { of a cold }\end{array}$ & & $\begin{array}{l}\text { Usually } \\
\text { have a } \\
\text { cough }\end{array}$ & $\begin{array}{l}\text { Usually } \\
\text { cough up } \\
\text { phlegm }\end{array}$ \\
\hline Great Britain ( $\mathrm{n}=27$ 507) & $13414(48.8)$ & $9155(33.3)$ & $634(9.6)$ & $1023(3.7)$ & $2427(8.8)$ & $1416(5.1)$ & $7850(28.5)$ & $5768(21.0)$ & $5736(20.9)$ & $8092(29.4)$ & $5795(21.1)$ \\
\hline \multicolumn{12}{|l|}{ Country $\dagger$} \\
\hline England ( $\mathrm{n}=20712)$ & $9913(47.9)$ & $6732(32.5)$ & $1908(9.2)$ & $729(3.5)$ & $1771(8.6)$ & $1059(5.1)$ & $5755(27.8)$ & $4255(20.5)$ & $4273(20.6)$ & $6283(30.3)$ & $4378(21.1)$ \\
\hline Wales $(\mathrm{n}=2351)$ & $1152(49.0)$ & 790 (33.6) & $212(9.0)$ & $87(3.7)$ & $212(9.0)$ & $123(5.2)$ & $698(29.7)$ & $480(20.4)$ & $513(21.8)$ & $720(30.6)$ & $496(21.1)$ \\
\hline Scotland $(n=4444)$ & $\begin{array}{c}2349 \\
(52.9)^{\star *}\end{array}$ & $\begin{array}{c}1633 \\
(36.7)^{\star \star}\end{array}$ & $\begin{array}{c}514 \\
(11.6)^{\star \star}\end{array}$ & $\begin{array}{c}207 \\
(4.7)^{*}\end{array}$ & $\begin{array}{c}444 \\
(10.0)\end{array}$ & $\begin{array}{l}234 \\
(5.3)\end{array}$ & $\begin{array}{c}1397 \\
(31.4)^{\star}\end{array}$ & $\begin{array}{c}1033 \\
(23.2)^{*}\end{array}$ & $\begin{array}{c}950 \\
(21.4)\end{array}$ & $\begin{array}{c}1089 \\
(24.5)^{\star \star \star}\end{array}$ & $\begin{array}{l}921 \\
(20.7)\end{array}$ \\
\hline \multicolumn{12}{|l|}{ Areał } \\
\hline Metropolitan ( $\mathrm{n}=9902)$ & $4519(45.6)$ & $3000(30.3)$ & $822(8.3)$ & $385(3.9)$ & $795(8.0)$ & $484(4.9)$ & $2515(25.4)$ & $1876(18.9)$ & $1881(19.0)$ & $3211(32.4)$ & $2258(22.8)$ \\
\hline $\begin{array}{l}\text { Non-metropolitan } \\
\quad(\mathrm{n}=17 \mathrm{605})\end{array}$ & $\begin{array}{c}8895 \\
(50.5)^{\star \star \star}\end{array}$ & $\begin{array}{c}6155 \\
(35.0)^{\star \star \star \star}\end{array}$ & $\begin{array}{c}1812 \\
(10.3)^{* * *}\end{array}$ & & & $\begin{array}{l}932 \\
(5.3)\end{array}$ & $\begin{array}{c}5335 \\
(30.3)^{\star \star \star}\end{array}$ & $\begin{array}{l}3892 \\
(22.1)^{\star * \star}\end{array}$ & $\begin{array}{c}3855 \\
(21.9)^{\star \star \star \star}\end{array}$ & $\begin{array}{c}4881 \\
(27.7)^{\star \star \star *}\end{array}$ & $\begin{array}{c}3537 \\
(20.1)^{\star *}\end{array}$ \\
\hline \multicolumn{12}{|c|}{ England and Wales quadrants } \\
\hline South West $(n=5901)$ & $2806(47.6)$ & $1957(33.2)$ & $538(9.1)$ & $3(3.6)$ & $535(9.1)$ & $312(5.3)$ & $1675(28.4)$ & $1235(20.9)$ & $1242(21.0)$ & $1803(30.6)$ & $1198(20.3)$ \\
\hline South East $(n=7482)$ & $3552(47.5)$ & $2418(32.3)$ & $702(9.4)$ & $240(3.2)$ & $644(8.6)$ & $375(5.0)$ & $2100(28.1)$ & $1536(20.5)$ & $1549(20.7)$ & $2191(29.3)$ & $1533(20.5)$ \\
\hline North East $(n=5719)$ & $2903(50.8)$ & 1949 (34.1) & $528(9.2)$ & $228(4.0)$ & $488(8.5)$ & $298(5.2)$ & $1619(28.3)$ & $1214(21.2)$ & $1197(20.9)$ & $1767(30.9)$ & $1313(23.0)$ \\
\hline North West $(\mathrm{n}=3961)$ & $1804(45.5)$ & $1198(30.2)$ & $352(8.9)$ & $135(3.4)$ & $316(8.0)$ & $197(5.0)$ & $1059(26.7)$ & 750 (18.9) & $798(20.1)$ & $1242(31.4)$ & $830(21.0$ \\
\hline \multicolumn{12}{|l|}{ NHS region (1993) } \\
\hline South West $(n=2707)$ & $1330(49.1)$ & $955(35.3)$ & $294(10.9)$ & $84(3.1)$ & $259(9.6)$ & $139(5.1)$ & $837(30.9)$ & $631(23.3)$ & $564(20.8)$ & 773 (28.6) & $543(20.1)$ \\
\hline South Thames $(n=2297)$ & $1086(47.3)$ & $720(31.3)$ & $223(9.7)$ & $78(3.4)$ & $203(8.8)$ & $110(4.8)$ & $616(26.8)$ & $448(19.5)$ & $470(20.5)$ & $712(31.0)$ & $527(22.9)$ \\
\hline North Thames (n=2220) & $980(44.1)$ & 676 (30.5) & $165(7.4)$ & $73(3.3)$ & $171(7.7)$ & $100(4.5)$ & $575(25.9)$ & $400(18.0)$ & $404(18.2)$ & 654 (29.5) & $408(18.4)$ \\
\hline $\begin{array}{l}\text { East Anglia and Oxford } \\
\qquad(\mathrm{n}=2324)\end{array}$ & $1178(50.7)$ & 798 (34.3) & $238(10.2)$ & $68(2.9)$ & $209(9.0)$ & $131(5.6)$ & $705(30.3)$ & $545(22.6)$ & $530(22.8)$ & $617(26.5)$ & $476(20.5)$ \\
\hline West Midlands ( $\mathrm{n}=2219$ ) & $987(44.5)$ & $665(30.0)$ & $177(8.0)$ & $82(3.7)$ & $188(8.5)$ & $122(5.5)$ & $556(25.1)$ & $416(18.7)$ & 459 (20.7) & 741 (33.4) & 435 (19.6) \\
\hline Trent $(n=2207)$ & $1144(51.8)$ & $742(33.6)$ & $194(8.8)$ & $80(3.6)$ & $180(8.2)$ & $108(4.9)$ & $613(27.8)$ & $452(20.5)$ & $492(22.3)$ & $660(29.9)$ & $515(23.3)$ \\
\hline North West $(\mathrm{n}=3029)$ & $1358(44.8)$ & $910(30.0)$ & $272(9.0)$ & $106(3.5)$ & $238(7.9)$ & $147(4.9)$ & $790(26.1)$ & $579(19.1)$ & $601(19.8)$ & $947(31.3)$ & $635(21.0)$ \\
\hline $\begin{array}{l}\text { North East and } \\
\text { Yorkshire ( } \mathrm{n}=\end{array}$ & $1850(49.9)$ & $1266(34.1)$ & $345(9.3)$ & $158(4.3)$ & $323(8.7)$ & $202(5.4)$ & $1063(28.7)$ & $804(21.7)$ & $753(20.3)$ & $1179(31.8)$ & $839(22.6)$ \\
\hline Missing ( $n=27$ 507) & $427(1.6)$ & $469(1.7)$ & $417(1.5)$ & $403(1.5)$ & $479(1.7)$ & $406(1.5)$ & $413(1.5)$ & $498(1.8)$ & $733(2.7)$ & $365(1.3)$ & $428(1.6)$ \\
\hline
\end{tabular}

\section{${ }^{*} \mathrm{P}<0.05,{ }^{*} \mathrm{P}<0.01,{ }^{* *} \mathrm{P} \leqslant 0.001$}

†Two sample $t$ test comparing prevalence in Scotland with England.

$\ddagger$ Two sample $t$ test comparing prevalence in metropolitan and non-metropolitan areas.

(1.9\%, 520/27 507), 6 (1.2\%, 336/27 507), and 7-8 $(2.4 \%, 668 / 27507)$ compared with question 2 and in their answer to question 2 compared with question $1(0.4 \%$, 95/27 507). Prevalence figures were not adjusted for these inconsistencies.

Cluster sampling had little impact on prevalence estimates but produced wider confidence intervals and fewer statistically significant tests. For example, the overall prevalence of wheeze in the past 12 months was $33.3 \%$ (9155/27 507) (95\% confidence interval 32.7\% to $33.8 \%$ ) using individual level prevalences compared with $33.1 \%(\mathrm{n}=93)(31.9 \%$ to $34.4 \%)$ using the mean school level prevalences.

Nearly half of all respondents (49\%) had ever experienced wheezing, and a third reported wheezing in the past 12 months (table 2). This compares with one in five recalling a diagnosis of asthma at any time. Within the past 12 months $9.6 \%$ of all respondents had experienced four or more attacks of wheeze, $8.8 \%$ had speech limiting wheeze, and $3.7 \%$ had frequent nocturnal wheeze. One in $20(5.1 \%)$ reported that wheeze symptoms interfered with their daily activities to a moderate or greater degree.

Wheeze in the past 12 months was more common in pupils aged $>13$ (odds ratio 1.15 (95\% confidence interval 1.09 to 1.22$)$ ) and in girls (1.14 (1.08 to 1.20)) and less common in pupils born outside Great Britain (0.66 (0.57 to 0.77$))$. Ever having had asthma, in contrast, did not vary with age (odds ratio for age $>13$ $1.04(0.98$ to 1.11$))$ and was less common in girls $(0.79$
(0.75 to 0.84 ) and again less common in pupils born abroad (0.57 (0.47 to 0.68$))$.

\section{Geographical variation}

Most asthma symptoms and diagnosis of asthma showed a less than 1.3-fold variation from minimum to maximum at any geographical level. The prevalence of four or more attacks of wheeze in the past 12 months did vary across regions to a greater extent, from $7 \%$ to $11 \%$.

At a national level, Scotland had slightly higher levels of wheeze than England, differences that were often statistically significant $(36.9 \%$ v $32.3 \%$ for prevalence of wheeze in past 12 months, $\mathrm{P}<0.001)$. The higher prevalence persisted after adjusting for the older age of Scottish pupils. The prevalence of ever having had asthma did not differ between the two countries $(\mathrm{P}=0.75)$, but levels of cough or phlegm in the absence of colds were lower in Scotland than in England (table 2).

Non-metropolitan areas had higher prevalences of most wheeze symptoms and diagnosis of asthma than did metropolitan areas but lower prevalences of cough and phlegm in the absence of colds. These differences, though small, were significant (table 2) and were not accounted for by differences in the distribution of pupils born outside Great Britain.

There was no north-south or east-west geographical gradient in the prevalence of asthma symptoms or diagnosis within England and Wales. 


\section{Diagnosis and treatment of asthma}

Table 3 shows the percentage of pupils reporting wheeze symptoms who reported ever having a diagnosis of asthma. A diagnosis of asthma was reported by half of pupils reporting wheeze in the past 12 months and over three quarters of pupils who had wheeze causing a moderate or greater interference with daily activities. However, 33.8\% (342/1012) of pupils reporting frequent nocturnal wheeze in the past 12 months had no diagnosis of asthma.

Of the $5736(21 \%)$ of pupils who had ever had asthma, 75.7\% (4341) were symptomatic in the past 12 months, with 25.7\% (1475) recalling speech limiting wheeze, $11.7 \%$ (670) having weekly disturbances of sleep by wheeze, and $18.5 \%$ (1058) experiencing moderate or greater interference with daily activities $-3.9 \%$ (1058/27507) of the total sample.

Overall, $19.8 \%(5438 / 27507)$ of pupils had received drug treatment for wheezing and asthma in the past 12 months and 15.8\% (4353) had used inhalers. About 75\% (4259/5736) of pupils who had ever had a diagnosis of asthma had used an inhaler in the past 12 months (table 4), but 38.6\% (395/1023) of those who reported frequent nocturnal wheeze and $35.2 \%(927 / 2634)$ of those reporting four or more attacks of wheezing had not $(1.4 \%$ and $3.4 \%$ of total sample respectively).

\section{Geographical variation}

Levels of diagnosis of asthma (table 3) and use of inhalers (table 4) in symptomatic pupils were consistently higher in non-metropolitan areas, but variations between other geographical areas were less consistent. At a national level, Wales showed higher levels of asthma diagnosis and inhaler use in pupils with most wheeze symptoms but not those with symptoms of cough and phlegm. At a regional level, the proportion of pupils with any wheeze in the past 12 months who had used an inhaler in that time showed little variation, from $38.9 \%$ in North East and Yorkshire to $45 \%$ in East Anglia and Oxford.

\section{Discussion}

The prevalence of asthma symptoms (33.3\% for wheezing in the past 12 months), ever having had a diagnosis of asthma (20.9\%), and current use of an inhaler (15.8\%) reported by 12-14 year old schoolchildren was high throughout Great Britain. The levels were higher than in previous studies in younger children or broader age groups based on parental reports. $^{2-15}$ The levels were also slightly higher than those found in the 1991 ISAAC pilot study in 13-14 year olds in west Sussex, ${ }^{16}$ where the prevalence of wheezing in the previous 12 months was 29\%. However, the geographical variation of most symptoms and diagnosis of asthma varied by a factor of 1.3 or less across Great Britain. This variation is small compared with the global variation, within which the British prevalences are among the highest. ${ }^{17}$

The ISAAC questionnaire has been tested and validated. ${ }^{816}$ Its validity and repeatability have been confirmed in relation to bronchial hyperreactivity ${ }^{18}$ and doctor diagnosed asthma ${ }^{19}$ and are similar to those of

Table 3 Geographical distribution of self reported wheeze and cough in schoolchildren aged 12-14 years in Great Britain who reported ever having had a diagnosis of asthma

Wheeze in past 12 months

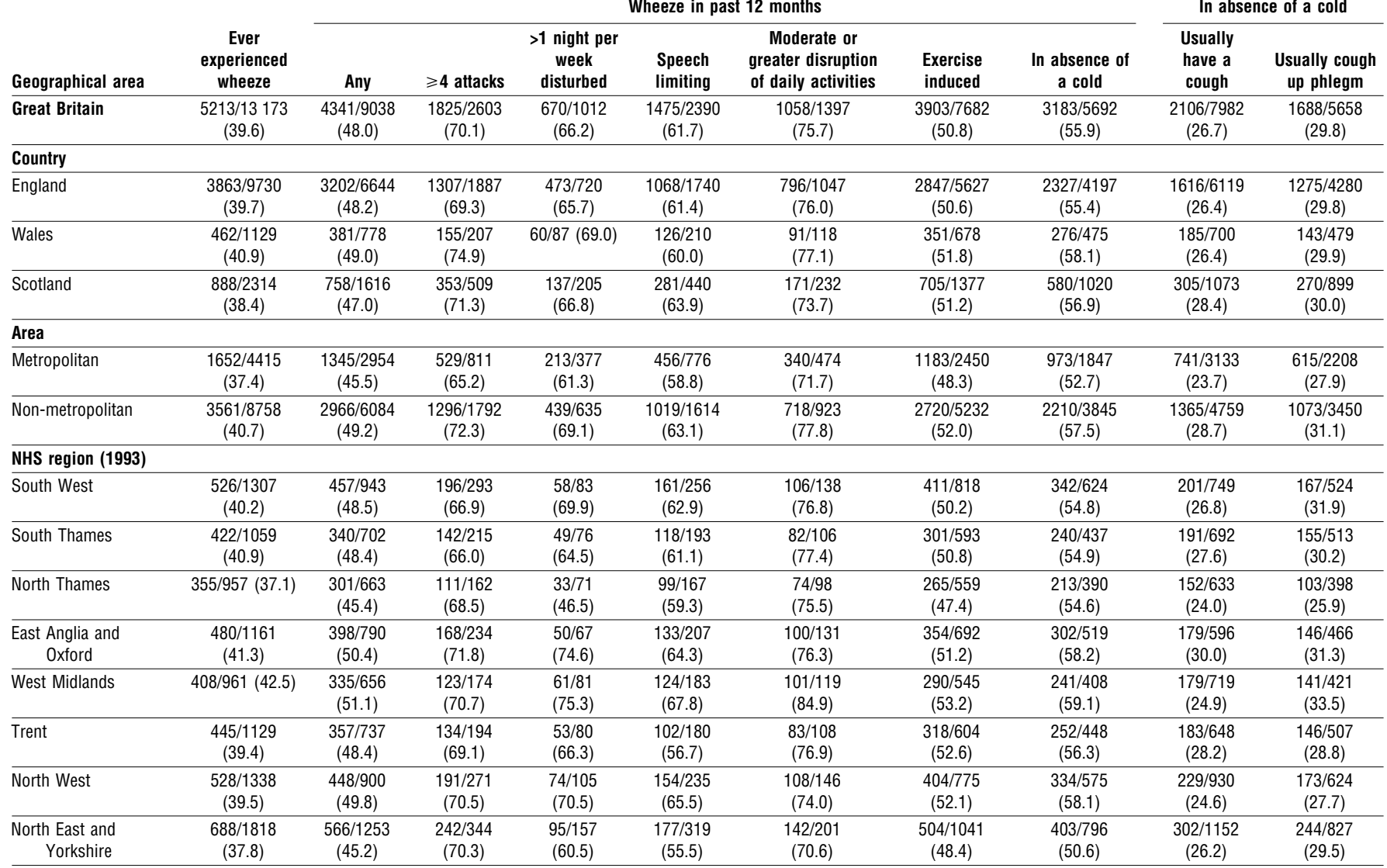


Table 4 Geographical distribution of self reported wheeze and cough in schoolchildren aged 12-14 years in Great Britain who reported using an inhaler within the past 12 months

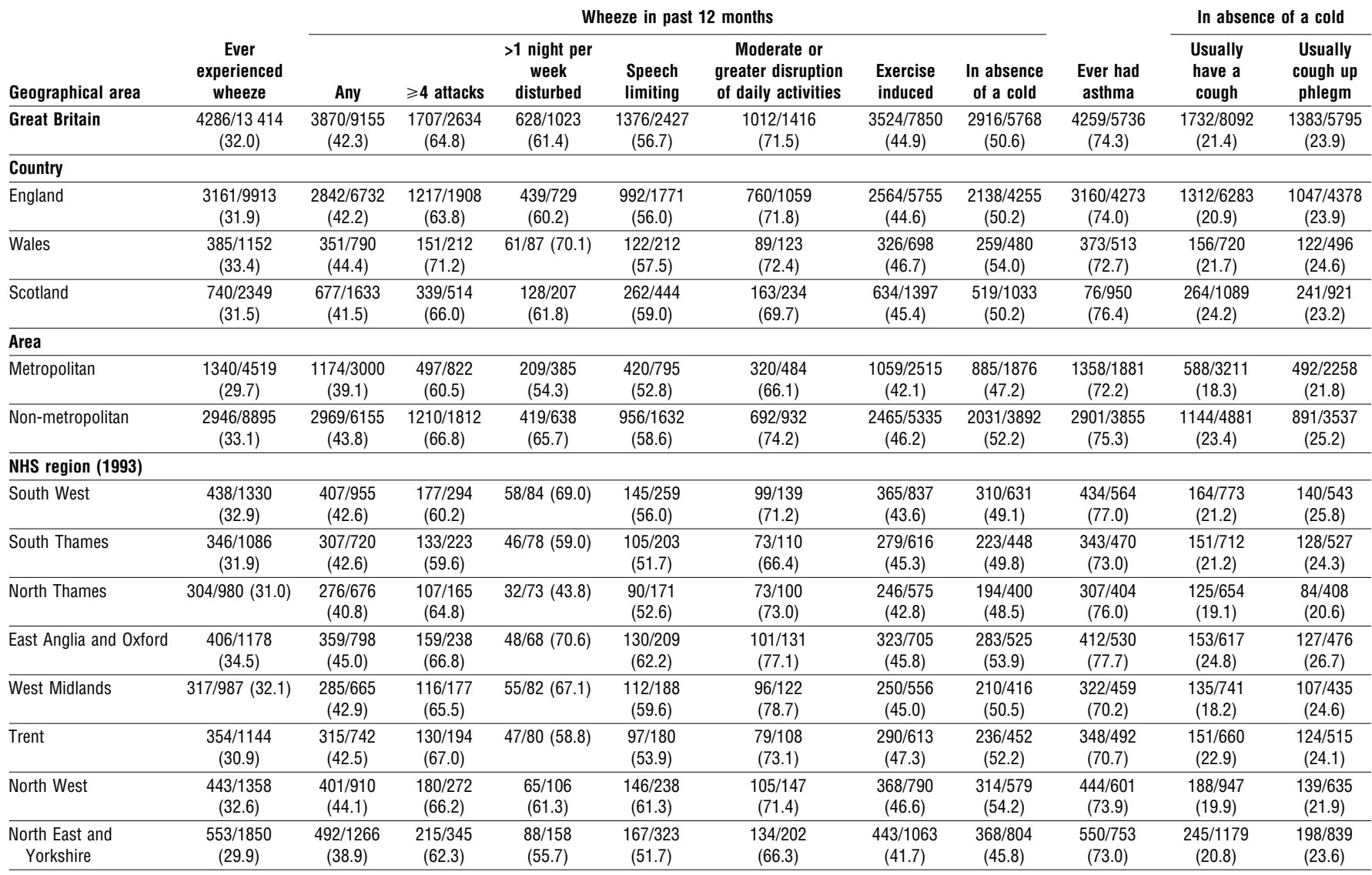

questionnaires for adults. ${ }^{20}$ In relation to clinically confirmed asthma, an Australian study found that consistent responses to the first two questions (any wheezing ever and any wheeze within the past 12 months) had a sensitivity of $85 \%$, specificity of $91 \%$, and positive and negative predictive values of $61 \%$ and $94 \%$ respectively. ${ }^{19}$

\section{Geographical variation in prevalence}

Within Great Britain, Scotland has a higher prevalence of wheeze symptoms but not of diagnosis of asthma than England; though the difference was small, it was significant. This contrasts with previous national studies, which found the lowest symptom prevalences in Scotland, ${ }^{21-23}$ but is consistent with levels found more recently in the Highlands ${ }^{24}$ and Aberdeen. ${ }^{13}$ The higher prevalence in Scotland is not explained by the older age of Scottish pupils. A non-response bias might have occurred, as Scotland had the lowest response rates at school level. However, these schools cited involvement in other studies as the reason for refusal, which was unrelated to our research question. Pupil response rates at the levels of region, quadrant, metropolitan area, and country were similar. Non-response bias could have resulted in an underestimate of prevalence if absence rates among children with asthma were higher and varied by region or area.

The higher prevalence of both wheeze and diagnosis of asthma in non-metropolitan areas than in metropolitan areas, while significant, was also small. This is consistent with the findings of the only other nationwide survey to analyse prevalence in this way, ${ }^{22}$ but it does not preclude the existence of higher prevalence in inner urban areas as reported by the national study of health and growth. ${ }^{25}$ The higher prevalence of symptoms in non-metropolitan schools was not due to differences in response rates or the distribution of pupils born abroad, though questionnaire bias might have operated if there were differences in reading and language ability between the two areas.

The lack of any regional variation of wheeze and asthma prevalence within England and Wales is consistent with previous national studies showing little variation at age $11^{21}$ and in 5-17 year olds. ${ }^{22}$

\section{Diagnosis and treatment of asthma}

Tables 3 and 4 indicate the potential unmet need for asthma treatment at various levels, including NHS regions: $4 \%$ of pupils reported having had a diagnosis of asthma but were still experiencing moderate or greater disruption of their lives, while a further $1-3.4 \%$ - that is, up to 6-7 pupils aged 12-14 at each large secondary school-reported moderate to severe symptoms but were undiagnosed and untreated. Symptomatic pupils were more likely to have had asthma diagnosed and treated with inhalers if they lived in non-metropolitan areas compared with metropolitan areas. In non-metropolitan areas three out of 10 pupils who had experienced four or more asthma attacks or weekly disturbance of sleep by wheeze over the past year were undiagnosed, compared with four out of 10 in metropolitan areas. This may reflect better quality of care in non-metropolitan areas. It remains a concern that, even allowing for misclassification by the 
Key messages

- We investigated the prevalence of self reported symptoms, diagnosis, and treatment of asthma in 12-14 year old children in Great Britain

- A third of subjects reported wheezing in the past year, and a fifth reported ever having had a diagnosis of asthma-higher prevalences than reported previously

- Prevalences of symptoms generally varied by a factor of 1.3 or less across Great Britain but, in contrast to previous reports, were significantly higher in Scotland than England and in non-metropolitan areas than metropolitan ones

- Asthma may still be undiagnosed and undertreated $-4 \%$ of pupils reported having had a diagnosis of asthma but were still experiencing moderate or greater disruption of their lives, while $1-3.4 \%$ reported moderate to severe symptoms but were undiagnosed and untreated

- The limited geographical variation in prevalences of symptoms and diagnosis of asthma suggests that the causes of asthma are widely distributed in Great Britain and that factors which do vary geographically-such as climate, diet, and outdoor environment-are not the main determinants of prevalence.

questionnaire, a substantial proportion of adolescents with asthma symptoms that interfered with their daily lives were not treated for the disease.

\section{Conclusions}

The lack of substantial geographical variation in prevalence of asthma symptoms in this age group suggests that the causes of asthma are already widely distributed in Great Britain. This makes it difficult to investigate causes by exploiting geographical variation, as epidemiological studies of disease aetiology require a distribution of exposures in the study base that lead to a varying distribution of disease. Furthermore, it suggests that factors which do vary geographically in Great Britain-such as climate, diet, and outdoor environment-are not the main determinants of prevalence. The lower prevalence of asthma symptoms in children born outside, but currently living in, Great Britain does suggest a role for the environment in early life, which could be investigated in new migrant populations. The causes of asthma may, however, be more readily identified by exploring the greater global variation, in which Great Britain shows some of the highest levels of asthma and wheeze.

We thank the National Asthma Campaign for funding; the departments of education in England, Wales, and Scotland for providing data on schools; the directors of public health for confirming details of local ethics committees; ethics committees for approving the study protocol; field workers who assisted with data collection and coding; and the head teachers, teachers, pupils involved at the 93 schools.

Contributors: HRA, JA, MB, DPS, and JOW conceived of the original idea; $\mathrm{BK}$ and HRA performed the literature review; $\mathrm{BK}$, HRA, JA, MB, DPS, and JOW designed the study; and all the authors were responsible for collecting and analysing data, interpreting the results, and writing the article. BK is guarantor of the article.

Funding: National Asthma Campaign.

Conflict of interest: None.

\section{Appendix 1: Respiratory questions in ISAAC} questionnaire

1. Have you ever had wheezing or whistling in the chest at any time in the past? Yes/No

If you have answered "No" please skip to question 11

2. Have you had wheezing or whistling in the chest in the last 12 months? Yes/No

If you have answered "No" please skip to question 11

3. How many attacks of wheezing have you had in the last 12 months? None/1-3/4-12/More than 12

4. In the last 12 months, how often, on average, has your sleep been disturbed due to wheezing? Never woken with wheezing/Less than one night per week/One or more nights per week

5. In the last 12 months, has wheezing ever been severe enough to limit your speech to only one or two words at a time between breaths? Yes/No

6. In the last 12 months, how much did this wheezing interfere with your daily activities? Not at all/A little/A moderate amount/A lot

\section{Exercise}

7. In the last 12 months, has your chest sounded wheezy during or after exercise? Yes/No

8. In the last 12 months, has your chest sounded wheezy when you HAD NOT recently taken exercise? Yes/No

\section{Colds}

9. In the last 12 months, have you had wheezing or whistling in the chest when you HAD a cold or flu? Yes/No

10. In the last 12 months, have you had wheezing or whistling in the chest when you DID NOT have a cold or flu? Yes/No

11. Have you ever had asthma? Yes/No

12. In the last 12 months, have you taken any treatment (medicines, tablets, inhalers) for wheezing or asthma? Yes/No

If "Yes," what?

\section{Inhaler \\ Yes-Name/Describe \\ No \\ Medicine/Tablets \\ Yes-Name/Describe \\ No}

\section{Cough}

13. In the last 12 months, have you had a dry cough at night, apart from a cough associated with a cold or chest infection? Yes/No

14. Do you usually have a cough when you HAVE a cold? Yes/No

15. Do you usually have a cough when you DO NOT have a cold? Yes/No

\section{Phlegm}

16. Do you usually seem congested in the chest or cough up phlegm (mucus) when you HAVE a cold? Yes/No

17. Do you usually seem congested in the chest or cough up phlegm (mucus) when you DO NOT have a cold? Yes/No 18. In the last 12 months, how many times have you had a cold or flu? (tick one answer only) Never/1-3 times/4-6 times $/ 7$ or more times

(This full text of questions-with instructions, options, and skips indicated-does not reflect the layout of the questionnaire.)

1 Office of Population Censuses and Surveys. General household survey. London: HMSO, 1988. (Series OHS.) 
2 Ninan TK, Russell G. Respiratory symptoms and atopy in Aberdeen schoolchildren: evidence from two surveys 25 years apart. $B M J$ 1992;304:873-5

3 Burr ML, Butland BK, King S, Vaughan-Williams E. Change in asthma prevalence: two surveys 15 years apart. Arch Dis Child 1989;64:1452-6.

4 Anderson HR, Butland BK, Strachan DP. Trends in the prevalence and severity of childhood asthma. BMJ 1994;308:1600-4.

5 Lewis S, Butland B, Strachan D, Bynner J, Richards D, Butler N, et al. Study of the aetiology of wheezing illness at age 16 in two national British birth cohorts. Thorax 1996;51:6706.

6 Central Health Monitoring Unit. Asthma-An epidemiological overview. London: HMSO, 1995. (Epidemiological overview series 1.)

7 Anderson HR, Esmail A, Hollowell J, Limejohns P, Strachan DP. Lower respiratory disease. In: Stevens A, Raftery J, eds. Health care needs assessment. Oxford: Radcliffe Medical Press, 1994: 256-332.

8 Asher MI, Keil U, Anderson HR, Beasley R, Crane J, Martinez F, et al. International study of asthma and allergies in childhood (ISAAC): rationale and methods. Eur Respir J 1995;8:483-91.

9 ISAAC (international study of asthma and allergies in childhood) manual. 2nd ed. Münster, Germany: Institut für Epidemiologie und Sozialmedizin, Universität, 1993: 3.

10 SAS Institute. SAS user's guide: basics, statistics, version 6. Cary, NC: SAS Institute, 1990.

11 Martin Bland. Clinstat. St George's Hospital Medical School, London: Martin Bland, 1994.

12 StatXact, version 2. Cambridge, MA: Cytel Software Corporation, 1991.

13 Omran M, Russell G. Continuing increase in respiratory symptoms and atopy in Aberdeen schoolchildren. BMJ 1996;312:34.

14 Whincup PH, Cook DG, Strachan DP, Papacosta O. Time trends in respiratory symptoms in childhood over a 24 year period. Arch Dis Child 1993;68:729-34.

15 Rona RJ, Chinn S, Burney PG. Trends in the prevalence of asthma in Scottish and English primary school children 1982-1992. Thorax 1995;50:992-3.

16 Pearce N, Weiland S, Keil U, Langridge P, Anderson HR, Strachan DP, et al. Self-reported prevalence of asthma symptoms in children in Australia, England, Germany and New Zealand: an international comparison using the ISAAC written and video questionnaires. Eur Respir J 1993;6: 1455-61.

17 Asher MI. ISAAC phase one: worldwide variations in the prevalence of wheezing and asthma in children [abstract]. Eur Respir J 1996;9(suppl 23): $410 \mathrm{~S}$.

18 Shaw R, Woodman K, Ayson M, Dibdin S, Winkelman R, Crane J, et al. Measuring the prevalence of bronchial hyper-responsiveness in children. Int J Epidemiol 1995;24:597-602.

19 Jenkins MA, Clarke JR, Carlin JB, Robertson CF, Hopper JL, Dalton MF, et al. Validation of questionnaire and bronchial hyperresponsiveness against respiratory physician assessment in the diagnosis of asthma. Int J Epidemiol 1996;25:609-16.

20 Burney PGJ, Laitinen LA, Perdrizet S, Huckauf H, Tattersfield AK, Chinn S, et al. Validity and repeatability of the IUTLAD (1984) bronchial symptoms questionnaire: an international comparison. Eur Respir J 1989;2: 940-5.

21 Strachan DP, Golding D, Anderson HR. Regional variations in wheezing illness in British children: effect of migration during early childhood. $J$ Epidemiol Community Health 1990;44:231-6.

22 Strachan DP, Anderson HR, Limb ES, O'Neill A, Wells N. A national survey of asthma prevalence, severity, and treatment in Great Britain. Arch Dis Child 1994;70:174-8.

23 Anderson HR, Britton J, Esmail A, Hollowell J, Strachan DP. Respiratory disease and sudden infant death syndrome. In: Botting B, ed. The health of our children. Decennial supplement. The registrar general's decennial supplement for England and Wales. 1st ed. London: HMSO, 1995: 111-32. (OPCS series DS No 11.)

24 Austin JB, Russell G, Adam MG, Mackintosh D, Kelsey S, Peck DF. Prevalence of asthma and wheeze in the highlands of Scotland. Arch Dis Child 1994;71:211-6.

25 Duran-Tauleria E, Rona RJ, Chinn S, Burney PG. Influence of ethnic group on asthma treatment in children in 1990-1: national cross sectional study. BMJ 1996;313:148-52.

(Accepted 16 September 1997)

\section{When I use a word ... What's my name?}

There is an ancient belief that one's name is one's identity, bound up with one's fate; the omen, so it has been said, is in the nomen. The power of knowing someone else's name is well illustrated by the fact that certain gods, notably Ra of the Egyptians and the Hebrew Yahweh, had secret and awful names, and also by the fairy tale about Rumpelstiltskin, the little man who was so certain that the well bred young princess would never guess that his name was Wrinkledforeskin.

Today, however, we seem to be less concerned about other people's names. The nurses, for example, call all our patients by their first names. My mother's reaction to this during her final illness was robust: when a nurse encouraged her to "come along, Sybil" her tart reply was "Don't you Sybil me!" On the other hand, a recent elderly patient of mine asked me to call her by her first name because, she said, it was more friendly; I acceded to her request, although a little uncertain about what exactly she expected from our relationship.

It is also surprising how seldom patients are asked how they pronounce or spell their names, even when the name is one whose pronunciation is obscure or whose spelling is difficult to guess from the pronunciation. Take, for instance, a patient called Sulc; everyone pronounced it sulk, but I suspected that it should be otherwise. My suspicions were confirmed when he told us-shoolts. Similarly, Babic was not babik but babitch (from a Russian word meaning [child of] an old woman). And was Gillett pronounced 'gi-let or ji-let? The former, as it turned out.

I am sensitive to this issue, because my own name has so often been misspelt and mispronounced, sometimes embarrassingly. I often receive letters addressed to "Aaronson." Other variants have included "Tronson," "Bronson," even "Arson." And old friends, even relatives, have been known to spell my first name Geoff.

Moses's brother was called Aharon. Although in English Aharon is transliterated as Aaron, on the
Continent it is more typically spelled Aron. The name was probably Egyptian and its meaning has been lost, but I prefer to think that it comes from Hebrew words meaning a mountain of strength, which Aharon had to be: Moses was a stammerer and Aharon had to speak to the Egyptian Pharaoh on the Jews' behalf. In Moses und Aron, the supreme opera about the difficulties of communication, Schönberg symbolised Moses's stammering by giving him a speaking part, in contrast to Aron's tenor.

At the start of a viva in my final undergraduate examinations one of our professors asked me why I pronounced my name 'â-ron-son. I said that it was because it was spelt with a single a. Oh no, he told me, a business acquaintance of his wife also spelt it with a single a, but he pronounced it 'ay-ron-son. No he doesn't, I said-he's my father. I passed the viva none the less.

On other occasions as a student, I had difficulty in conveying my name over the telephone to the lady who took the bookings at the university squash courts. "Name please," she would ask. "Aronson." "Anderson?" "No, Aronson-a-r-o-n-s-o-n." After a few such encounters I decide to change tactics: "Name please." "Aronson." "Anderson?” "That's it." Eventually it seemed easier just to say "Anderson" and have done with it. "Name please." "Anderson.” Pause.

"Armstrong?"

When there is even the slightest doubt, I ask patients how they pronounce and spell their names.

Jeff Aronson, clinical pharmacologist, Oxford

We welcome articles up to 600 words on topics such as A memorable patient, A paper that changed my practice, My most unfortunate mistake, or any other piece conveying instruction, pathos, or humour. If possible the article should be supplied on a disk. 